\title{
TRANSFORMING GEOLOGICAL AND LANDISLIDE SUSCEPTIBILITY MAPPING DATA TO LINKED (OPEN) DATA FOR HAZARD MANAGEMENT
}

\author{
Atzemoglou A. ${ }^{1}$, Kotzinos D. ${ }^{2}$, Grinias El. ${ }^{3}$, Spanou N. ${ }^{1}$ and Pappas Ch. ${ }^{4}$ \\ ${ }^{1}$ Institute of Geology \& Mineral Exploration (IGME), 1 Spirou Louis St., OLYMPIC VILLAGE, \\ ACHARNAE, P.C. 13677, matzem@thes.igme.gr \\ ${ }^{2}$ ETIS Lab, Department of Computer Science, University of Cergy - Pontoise, 95000 France, \\ Dimitrios.Kotzinos@u-cergy.fr \\ ${ }^{3}$ Department of Civil Engineering, Surveying and Geomatics, TEI of Central Macedonia, Terma \\ Magnisias Str., Serres, 62124, Greece, grinias@teiser.gr \\ ${ }^{4}$ Geomatics S.A., Zaimi 8, Athens, Greece, harpap83@gmail.com
}

\begin{abstract}
The frequent lack of information to populations exposed to landslides is a component of the social vulnerability and can strongly increase the risk on lives and infrastructures. Determining the extent of the landslide hazard requires identifying those areas which could be affected by a damaging landslide.

The users need to integrate different landslide data in order to first understand and then possibly become resilient to any potential catastrophic event. More precisely, public and private organizations can choose between different land use options to minimize the risk on the already existing infrastructures or to reduce the hazard itself through mitigation measures. From the other hand, the land use planners can also take best decisions before planning new infrastructures in high risk landslides' areas. Based on these data we have also implemented new tools, available every day and reusable by anyone interested, to identify land areas susceptible for landslides. The tools are based on cloud web services, especially for the management and presentation of these datasets in order to provide stakeholders with valuable information about past distribution of the landslides, type of bed rock, rainfall etc. in order to focus on land use policies and assess an impending landslide.
\end{abstract}

Keywords: geospatial data, sharing data, INSPIRE, semantic web, RDF.

\section{Пєрі́ $\lambda \psi \eta$}

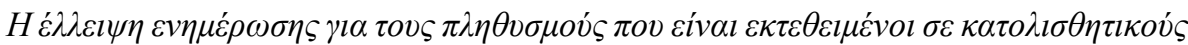

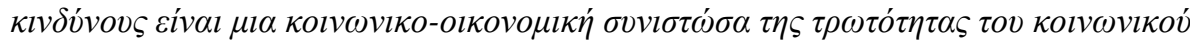

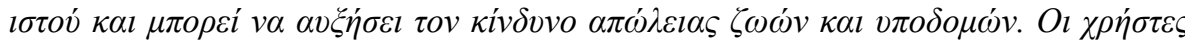

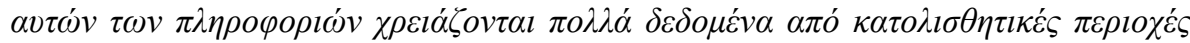

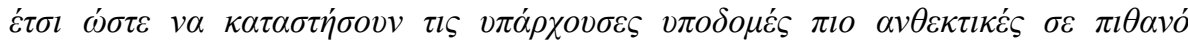

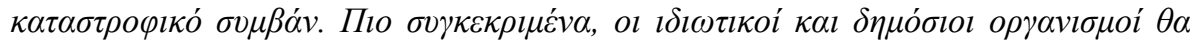

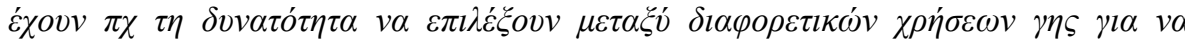

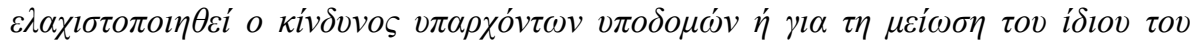

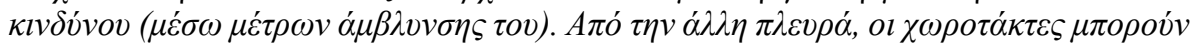

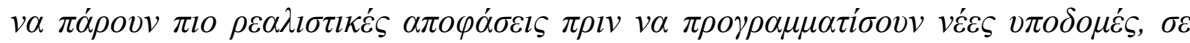




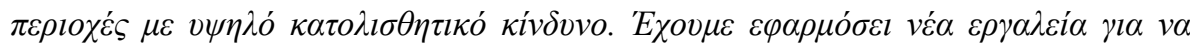

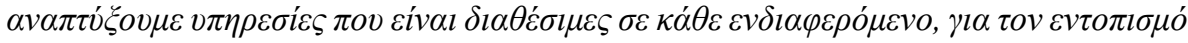

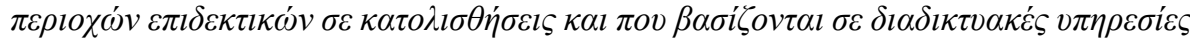

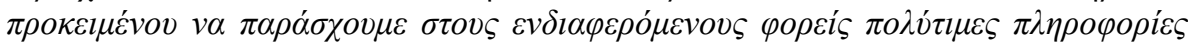

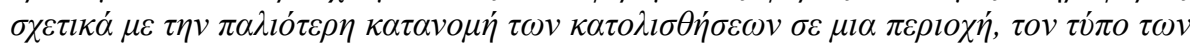

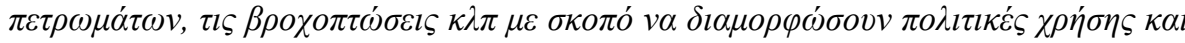

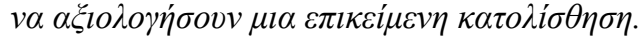

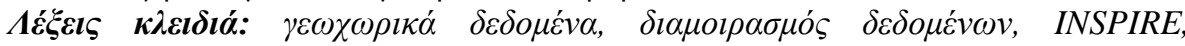

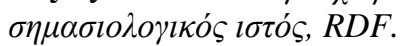

\section{Introduction}

Landslides are caused when gravitational forces pull rock or soil down a slope. Three physical factors are the minimum components necessary to assess landslide hazards; past history, slope steepness and bedrock. All these factors can be depicted on a geological map. The combination of these factors over a studied area results to a landslide hazard map.

\subsection{Necessity for the usage of landslides data to forecast catastrophic phenomena}

A landslide hazard map is the primary product that provides planners with a practical and costeffective way to zone areas susceptible to landsliding. It can be used as a tool to identify land areas best suited for development by examining the potential risk of landsliding. It is extremely difficult to predict landslide hazards, even with detailed investigation and monitoring. As a result, landslide hazard is often represented by landslide susceptibility (Brabb, 1984). Such a map is a valuable tool for assessing current and potential risks that can be used for developing early warning systems and mitigation plans, such as selecting the most suitable locations for construction of structures and roads (Chalkias et al., 2014). Decisions can then be made regarding which of these measures will be taken: avoidance, prevention, or mitigation of existing and future landslide hazards in a development program.

\subsection{End users and requirements}

On the other hand, the end users need accurate information for early warning like:

1. The occurrence of various triggering factors (e.g. regional or local weather and soils conditions),

2. The appearance of precursory evidences monitored over hazardous unstable areas.

Once landslides are identified for an area, the main requirement of the end users is to be provided with realistic answers to critical questions: what will happen, when, where, which way, for how long and how to mitigate it? Some of the key end users of such information systems are the national and local authorities, involved in civil protection, the technical agencies of the administrative regions, the plan makers, the infrastructure owners and operators etc.

\subsection{Phases of a landslide}

Depending on the phase of a disaster cycle, the end users have different approaches and requirements. One can distinguish 3 different phases of a land slide (Locat et al., 1997):

1. The pre-emergency phase where the soil is in a state of equilibrium and the rapture-related processes are active. The end user demand information on exposure of population or infrastructures in addition to information on landslides. The mitigation focus on land use policies while preparedness focus on operational tools for crisis management.

2. Short term to very short term phase. At this stage mechanisms are active to manage this emergency phase to assess or face an impending landslide. This happens during the triggering stage of the landslide. This phase is critical for the end users. During the crisis the end users' needs are updated maps for the affected areas, rapid evaluation of the damages and mitigation measures. 
3. The post-emergency phase concerns supplying end users with critical information to reduce consequences.

Each exposed site presents specific features that are critical to identify in order to provide the most relevant products that satisfy end users requirements at each phase of a disaster management cycle.

\section{Data description}

We decided to test the data collection process, their integration and their presentation through a cloud-based web information system and thus we have selected a pilot site (wider area of Karpenisi, $\mathrm{W}$. Greece) to acquire geospatial data, field measurements and other data such as classification, volume, activity, date of occurrence of landsliding etc. The studied area is $950 \mathrm{~km} 2$ while the total area covers $4000 \mathrm{~km} 2$. The population is 20,000 inhabitants. The studied area belongs to the prefectural units of Evritania and the neighbor of Karditsa, Fthiotida, Aitolia-Acarnania and Fokida (fig. 1). For the studied area we used 6 geological sheets published by IGME (scale 1:50000).

The area has steep slopes and a variety of altitudes while the positions of the landslides are recorded from 80 to $1550 \mathrm{~m}$. We used 334 landsliding events. 120 landslides belong to the study area while the rest covered the wider area of the municipality of Karpenisi. The used landslide inventory covers a long time period, from 1929 to 2010.

We have implemented a landslide inventory updated with remote sensing techniques and high accuracy aerial images which revealed new landslide areas not included to the existed inventory. This also validated the existing inventory increasing the accuracy of the model.

During the implementation of the database and before the creation of the final maps, we solved problems related to data redundancy (repetition of the same data) and data inconsistency (data corrections). The data are stored in the INGEOCLOUDS platform database (on the cloud) and are ready to be reused from the scientific community (data sharing).

\subsection{Geological setting of the selected area}

Geo-tectonically, the studied region is belonging to the Gavrovo - Tripolis and Olonos - Pindos geotectonic zones (from W to E).

The Pindos zone is a nappe that overthrusts the Tripolis zone. It consists from clastic upper Cretaceous - lower Tertiary sediments, Maestrichtian-Danian limestones and Pelagic radiolarites. The Pindos zone is faulted and folded from successive thrusts moved from east to west. The morphology of the relief, in the wider region, is mountainous with mild to steep slopes and strong contrasts (gorges, mild valley shapes etc.), differentiated according to the nature and place of geological structures, from the limestones to the flysch sediments, the alluvial fans and the talus slope. More specifically, the representative litho-stratigraphic column consists of U-M Triassic dolomites, limestones, sandstones and volcanic sediments, Jurassic hornfels, Cretaceous flysch and limestones and L. Oligocene to U. Eocene flysch.

The geotectonic zone of Gavrovo-Tripolis is considered as an autochthonous series over which the Pindos has been thrusted. The Tripolis zone is also thrusted over the western Ionian zone. The representative litho-stratigraphic column contains upper Paleozoic mica-schist, quartzites, phyllites and limestones, a large sedimentary series with upper Triassic dolomites, Jurassic and cretaceous limestones, and Oligocene flysch. The tectonic of this zone is characterized by a sequence of anticlines and synclines with many faults and strong displacements (Mountrakis, 1987). 


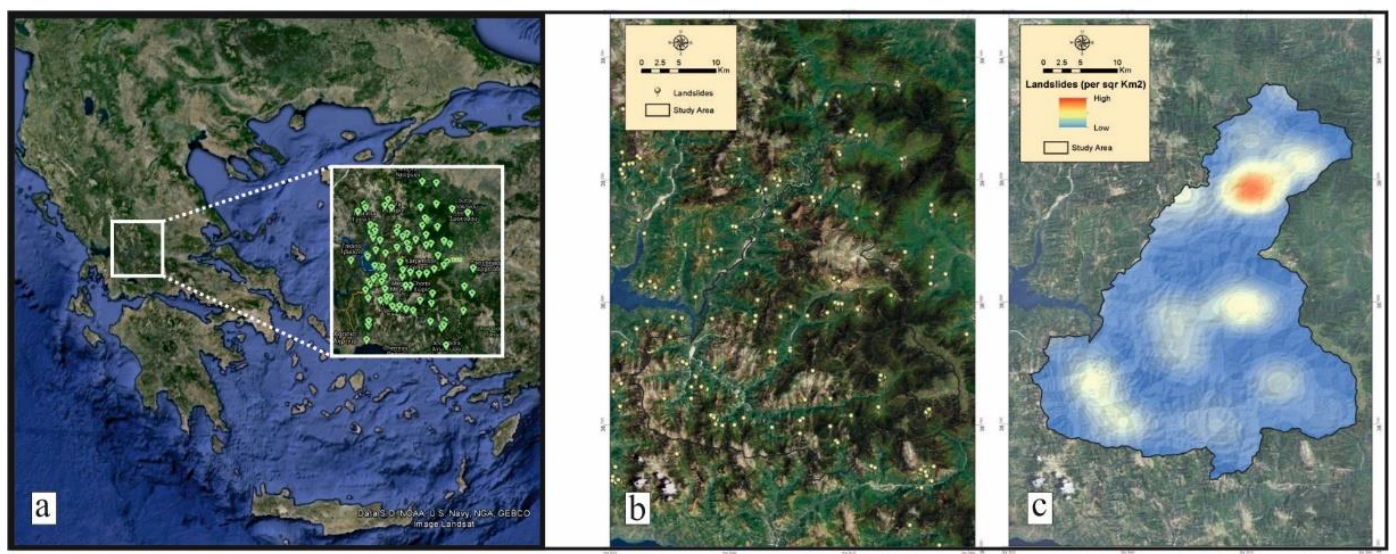

Figure 1 - Location map (a), inventory map (b) and density map (c) of the existing landslides for the study area.

\subsection{Susceptibility map creation}

In this study the landslide susceptibility model aims to provide information about the spatial distribution of the landslide occurrence in areas where no adequate information was available. It is critical to mention that the model does not provide information about the frequency nor the probability, type and effects of landslide events but only their probable future occurrence. For this study the landslide susceptibility mapping was conducted using a GIS model based on the Weightsof-Evidence (WoE) method (Petley et al., 2002; Bajracharya et al., 2005). WoE is a data-driven method applied where sufficient data are available to estimate the relative importance of evidential themes by statistical means (Bonham-Carte,r 1994; Bonham-Carter et al., 1989). This formulation of the Bayesian probability model was used to calculate the landslide susceptibility in the wider area of Karpenisi. The W.o.E is determined by the probability of the presence or absence of each of the classes within each of the predictor factors, in relation to the presence or absence of a past landslide at the same location. So it is worth to mention that all this statistical approaches requires an evaluation process because there is still a controversy about their reliability and accuracy (BonhamCarter et al., 1989; Thiery et al., 2007; Neuhauser et al., 2007).

\section{Materials and methods}

The main stages for the calculation of the landslide susceptibility map were: data collection and preparation, construction of the landslide inventory and the DEM. During the preparation stage a characterization between triggering and controlling factors of the landslide mechanisms were discussed in order to audit the provided data relevance. An important point for evaluating the results of this method is that the possibility of a landslide occurrence will be comparable with observed landslides. With the use of GIS it was easy to construct the controlling factors as thematic maps. The calculation of the model requires in general, various geographical (such as slope, aspect and land use) and geological data (lithology, faults, landslide inventory). All the factors (raster maps) were classified based on their characteristics and in order to calculate the weights of each one.

\section{Editing Process}

As dense as possible is the spatial distribution of the events the more accurate the results will be. So the used landslide inventory was digitized and organized according to INSPIRE directive [1] and JRC [2] guidelines and then converted into polygon areas. We also use remote sensing techniques and high accuracy aerial images in order to supplement and evaluate the current landslide inventory. We use the aerial photography provided by KTIMATOLOGIO S.A. and the landslide inventory was supplemented by interpreting earth's surface and derives landslide areas. The remote sensing techniques and radiometric adjustments enhanced the interpretation. 
The next step was to create the necessary factors for the calculation of the susceptibility map. Maps relevant to landslide occurrence were constructed using ARC-GIS. The factors used to create the model are: lithology which was developed by digitizing and combining information from the available geological maps published by IGME (scale of 1: 50 000); the digital elevation model (DEM) of the study area which was derived from $20 \mathrm{~m}$ elevation contours digitized from the existing topographic maps; the slope gradient directly controls the mechanisms which are responsible for the initiation of slope failures; the land use was also categorized as controlling factor (from the European Environment Agency project Corine [3]); the slope aspect, as derivative of DEM, which was used to inspect and include the parameter of the exposure of a slope to rainfall, wind and sunlight; the curvature, being the geometrical feature of topography, affects the hydrological conditions of the soil cover. The curvature map was derived from DEM analysis in ARC-GIS.

Classifying factors: The factors used were provided in vector or raster formats (table 1). The vector factors (land use, lithology) where converted into raster form and then classified according to the interpretation of their unique characteristics and their impact on the landslide phenomena. The "density slicing" remote sensing technique was used in order to discover patterns in the values of each thematic map and then decide about the classification of the maps.

Table 1 - Classification of factors.

\begin{tabular}{|c|c|}
\hline Factor & Class \\
\hline 1. Aspect (Degrees) & $\begin{array}{l}\text { Flat (-1), North (0-22.5), Northeast (22.5-67.5), East (67.5-112.5), Southeast } \\
\text { (112.5-157.5), South (157.5-202.5), Southwest (202.5-247.5), West (247.5- } \\
\text { 292.5), Northwest (292.5-337.5), North (337.5-360) }\end{array}$ \\
\hline 2. Land Use & $\begin{array}{l}\text { Urban fabric, mines, industrial units, Permanent crops, Forests, } \\
\text { Heterogeneous agricultural areas, Scrub and/or herbaceous vegetation, Open } \\
\text { spaces with little or no vegetation }\end{array}$ \\
\hline 3. Curvature & Concave, Less concave, Convex, Plan \\
\hline 4. Slope (Degrees) & $\begin{array}{l}0-5,5-10,10-15,15-20,20-25,25-30 \\
30-35,35-40,40-45,45-50,50-55,>55\end{array}$ \\
\hline 5. Lithology & $\begin{array}{l}\text { Alluvial, Talus cones and scree, Neogene sediments, Sandstones, Flysch, } \\
\text { Conglomerates, Volcanic rocks, Limestones, Ophiolites, Water Surfaces }\end{array}$ \\
\hline
\end{tabular}

Weighting process: The WoE was calculated for every factor. The idea for the probabilistic calculation is that landslides occurred in the past are connected with the weighting factors supposing that can trigger landslides. The next step was to calculate the landslide occurrence in every class of every factor, then compare it with the number of pixels (of each raster map) in every class of every factor etc.

Assigning weights to factors in GIS: In order to combine all the factors discussed and produce a probabilistic landslide susceptibility map, the calculated weights values were assigned to each factor by the standardized ranked values of its classes and summed the individual products, according to the equation:

$$
P=\sum\left(W_{j} * X_{i j}\right)
$$

Where $\mathrm{P}$ is the output pixel value, $\mathrm{Wj}$ is the $\mathrm{j}^{\text {th }}$ factor weight and $\mathrm{X}^{\mathrm{ij}}$ is the standardized rank value of the $\mathrm{i}^{\text {th }}$ class of the $\mathrm{j}^{\text {th }}$ factor. The equation is computed with the use of ARC-GIS raster calculator module. The output is a raster file with pixel values ranking from negative to positive values based on the weights computed by the W.o.E model. Results: The landslide susceptibility map was classified into five classes. From "Very low", "low", "moderate", "high" to "Very high". The results showed a logical correlation between the landslides that was mapped by IGME and the landslide susceptibility that was calculated with the use of W.o.E. Examining some factors, we can notice that applying W.o.E we reveal regions with high weight values (between $40^{0}-45^{0}$ ) while the landslide susceptibility increases at steep slopes $\left(>40^{0}\right)$. About the land use factor, we can notice that there is an increase in the weight values in areas where scrub and/or herbaceous vegetation exist where consequently the landslide susceptibility increases. 
The resulting landslide susceptibility map shows that several settlements are located within very High susceptibility areas and the majority of the road network lies in landslide-prone areas.

\section{Data transformation}

Publishing data at a large-scale usually means that many different and diverse datasets are made available through different data infrastructures. Users of these datasets are usually interested in combining information crossing through the available datasets regardless of origin, purpose or format. This means that we need eventually to deal with data integration issues at various levels and with various degrees of coupling. Data integration means, among other things, that we need to provide data end users with the notion that a single common well-managed data source exists instead of many- distributed or not - individual ones.

Overcoming this diversity is the objective of the recent W3C [4], the LOD (Linked Open Data initiative [5] for a unifying, machine-readable data representation that makes it possible to semantically access and interlink heterogeneous but (semi-)structured resources at data level. LOD has become a prominent choice for sharing (semi-) structured data on the web originating from heterogeneous sources. Linked Open Data offers great potential for building innovative applications that create new value from the already collected data. Thus LOD is an effort of integrating semantically described data on RDF [6] and thus, can be used for the creation of semantically interoperable data-spaces. To the best of our knowledge there is no similar work on publishing landslide related data as Linked Open Data that we can compare with.

In order to do that we need to express our data using tools and languages used by the semantic web. These include using RDF as the main languages of communication. Thus we account for the interoperability among the different datasets and by using SPARQL [7] as the main query language for managing the data and the metadata we provide a uniform way of retrieving this information. As various heterogeneous datasets from different thematic fields can be supplied by data providers, there is a need of not only describing the meta-data in a unified way, but also integrate them that allows minimal changes to the original formats.

To this end, a specific meta-model was created and described in RDF language accurately capturing the semantics of these thematic fields. This model was created by extending CIDOC CRM [8] standard meta-model for describing scientific/cultural data-sets (ISO 21127:20) through particular geo-spatial extensions that were based on ISO 19115, GML [9] and other standard models; the model has been kept as much as possible compliant to the corresponding INSPIRE model.

So in order to properly publish our data on the semantic web and link them with other (possibly external) resources we can describe them using RDF or OWL [10], we can query them using SPARQL and we can link them with other resources by providing unique URIs [11].

\subsection{Available data standards}

According to INSPIRE Directive Geo-spatial datasets are "data with a direct or indirect reference to a specific location or geographic area". A geospatial piece of information is defined by one (or more) attribute including spatial description of the object: coordinates $\mathrm{X}, \mathrm{Y}$ of the events, surface of the geologic unit, grid information for landslides. The OGC [12] and ISO/TC211 describe the definition of a geospatial object in the reference model described in ISO 19101 and model the different compositions of this object in ISO 19136. GML, ISO 19xxx family [13] specifications describe the encoding format of geospatial objects to exchange with services. INSPIRE's technical guides use these standards for the description of data.

\subsection{Natural hazards data in INSPIRE}

The landslides are described in two themes in the following INSPIRE annexes of the Directive: Annex II - Theme 4. Geology. 
Annex III - Theme 12. Natural risk zones (floods, landslides and subsidence, avalanches, forest fires, earthquakes, volcanic eruptions).

Annex III - Theme 7. Environmental monitoring facilities.

\subsection{INSPIRE compliant transformations}

This allows data providers to dynamically transform their data into INSPIRE compliant formats, using standardized tools and languages for these transformations since they have been published as Linked Open Data. This means that existing datasets can go through one process to be published and at the same time to be made available following the norms of the INSPIRE directive.

In the INGEOCLOUDS project [15] two different methods have been realized to allow exporting provider's data into XML-based [14] INSPIRE-compliant specifications: the inspire_export and the inspire_query_export.

\subsection{Final notes on modelling and transforming landslide related data}

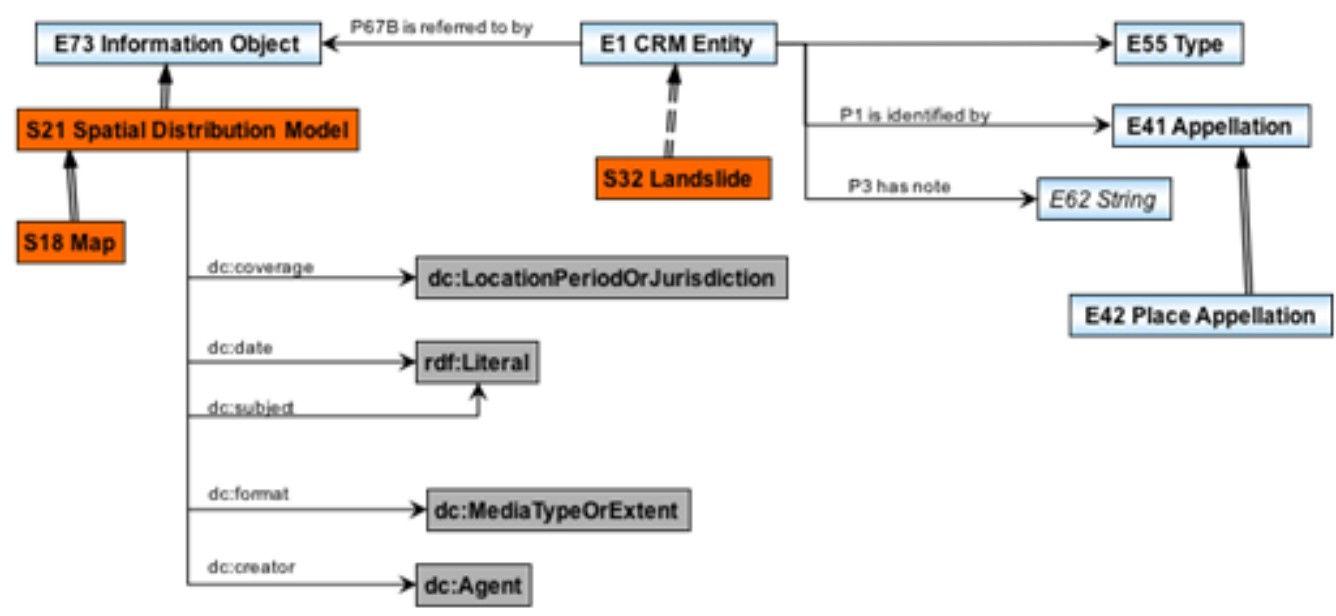

Figure 2 - An exert of the conceptual model, the part that represents landslides.

Landslides are an integral part of any conceptual model that wants to represent natural hazard related data. INSPIRE is doing an extensive effort to represent these data but unfortunately the effort is fragmented among different themes, each of them capturing a part of the overall available and necessary information. Thus we made the effort to represent a unified but complete model of landslide related data so (fig. 2) that they can be used in various applications; some of those were demonstrated during the life of INGEOCLOUDS project (www.ingeoclouds.eu).

\section{Description of services provided to end users}

\subsection{Final products (maps) and specific services}

The outputs produced and all the intermediate maps (fig. 3a) are available on the web and can be reused by anyone interested. The user can see the landslides events of the studied area, retrieve the available data from the database concerning the landslides' characteristics (longitude, latitude, municipality, year and season of landslide occurrence, altitude, precipitation, lithology, movement type, slope tilting, land cover), publishing his own landslides events and relevant information (fig. $3 \mathrm{~b}$ and c). These web services can re-use the maps as WMS [16] and contain much functionality. Enable also the user to select and display other maps available as WMS or WFS [16].

We have also implemented the Ordinary Kriging process in a cloud-based environment (WPS [16]) and coupled it with access to data stored as Linked Data described in RDF (Grinias et al, 2015; 
Atzemoglou et al., 2014). An example of Ordinary Kriging execution is graphically depicted in Figure $3 \mathrm{~d}$ and $3 \mathrm{e}$ using measurements for rainfall. These specific services are available through a WebGIS Client application which has built in the INGEOCLOUDS platform with the ability to fetch landslides vector data through queries and display them on a map.

\subsection{Combination with other data}

The landslide movements are relatively intense in the Greek area and are directly related to the relief, lithology and vegetation. Additional principal mechanisms for triggering a landslide are the earthquakes and the heavy precipitation events.
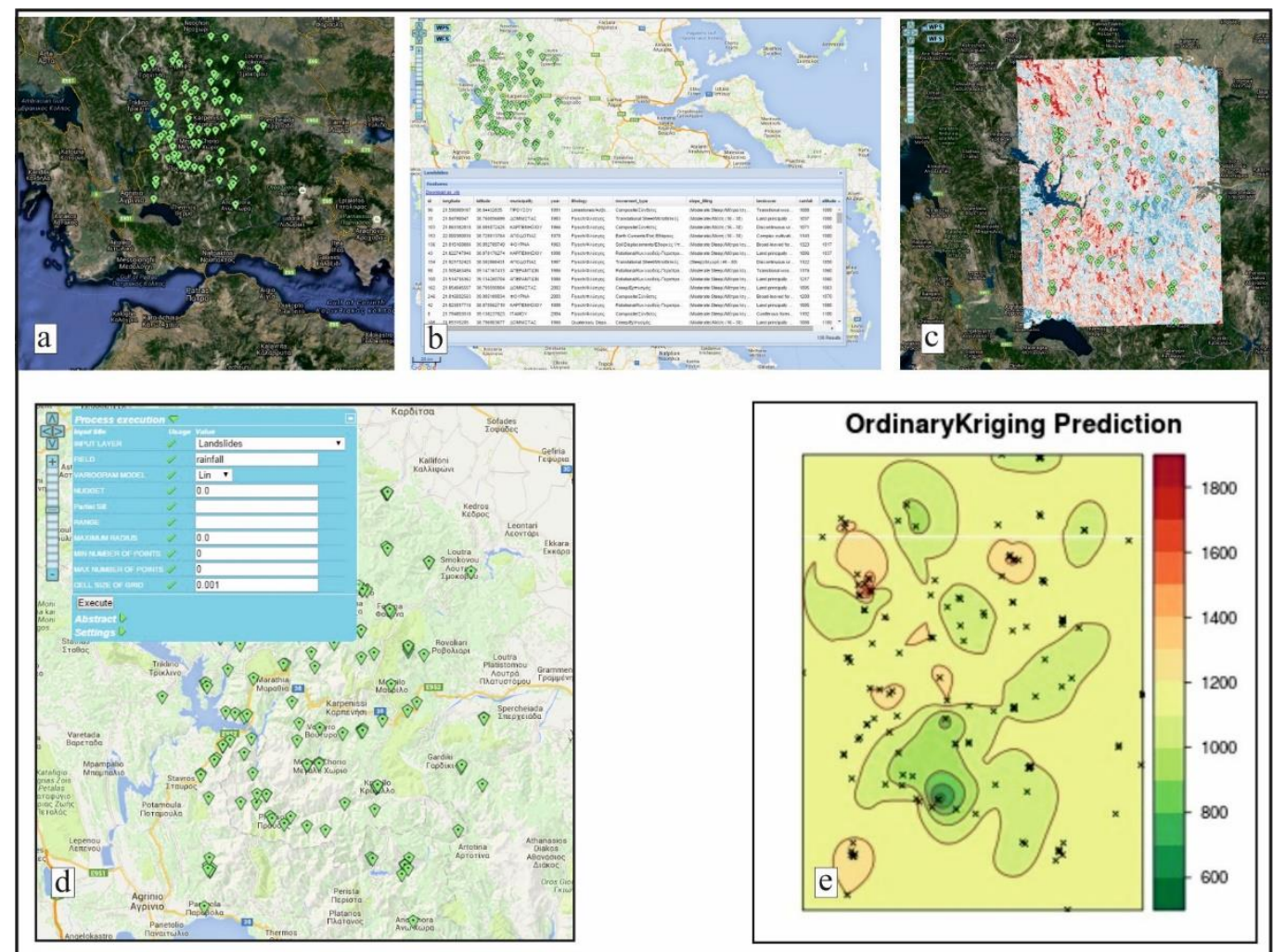

Figure 3 - (a) The available landslide events of the studied area (b) retrieval of the available data from the database, (c) the susceptibility map and the landslide events (d). The selected landslide's events (used for the kriging interpolation) and the panel for giving kriging parameters and input data (rainfall) and (e) preview of ordinary kriging output (the points with known values are depicted as black crosses).

\section{Earthquakes}

Many types of landslides are identified in earthquake caused ones. The most frequent are rock falls, disrupted soil slides, soil falls and rock slides. Each type of earthquake-induced landslide occurs in a particular geological environment (Keefer, 1984). Earthquake-induced landslides occur under a broad range of conditions; in steep slopes; in unconsolidated sediments; in un-compacted man-made fill etc. Complex structure and strong tectonic fracturing influence landslide occurrence in the Greek territory resulting in serious problems in population and the economy.

Vasileiadis (2010) put all the Greek recorded landslides' events on a thematic map with the seismic zones. The landslides occurrence directly connected with the seismic zone III $(0.36 \mathrm{~g})$ is $43.38 \%$ and with seismic zone II $(0.24 \mathrm{~g})$ is $38.54 \%$. Papadopoulos et al., 2000 have examined a data set of 47 earthquake-induced 
landslides occurring in Greece from 1650 to 1995 and the landslide distribution. Earthquakes triggering landslides range in magnitude from $\mathrm{Ms}=5.3$ to 7.9 , with peaks at Ms=6.4 and 6.7.

\section{Conclusions}

Inventory, density and susceptibility maps which are available for all those interested, assist the land use planning, assess the risk of possible threats, estimate the possible decrease of a property value and help construction companies to avoid regions with high possibilities of landslide danger. Making these data available as web services allow external stakeholders to integrate them directly into their software. In our case this happened by developing and providing an advanced information system that allows for visualization and management of the information. We use the cloud to store and disseminate the data since we can rely on its constant availability and the scalability of resources.

It is useful to mention that factors such as proximity to faults, distance from roads and rainfall data have been rejected as triggering factors because of they could not fit the validation process. The results when using these data was inconclusive.

The produced susceptibility map showed that several settlements are located within very highly susceptible areas, and that a major proportion of the road network lies in landslide-prone areas.

Combination of maps showing zones of seismic hazards provide the planner with data on considerations about the spatial application of building codes and the need for local landslide and flood protection.

\section{Acknowledgments}

This work was partially supported by INGEOCLOUDS (2012-2014), a project partially funded by the EU CIP program with Grant Agreement No 297300.

\section{References}

Atzemoglou, A., Roussakis, Y., Kritikos, K., Lappas, I., Grinias, E. and Kotzinos, D., 2014. Transforming geological and hydrogeological data to linked (open) data for groundwater management, $10^{\text {th }}$ International Hydrogeologicla Congress of Greece, Thessaloniki.

Bajracharya, B. and Bajracharya, S.R., 2005. Landslide mapping of the Everest region using high resolution satellite images and $3 \mathrm{D}$ visualization, International Centre for Integrated Mountain Development (ICIMOD).

Bonham-Carter, G.F., Agterberg, F.P. and Wright, D.F., 1989. Weights of evidence modelling: a new approach to mapping mineral potential. In: Agterberg, F.P. and Bonham-Carter, G.F., eds., Statistical applications in earth sciences, 171-183, Ottawa (Geol. Survey Canada).

Brabb, E., 1984. "Innovative Approaches to Landslide Hazard and Risk Mapping" in IV International Symposium on Landslides, 1, 307-323.

Chalkias,C., Ferentinou, M. and Polykretis, C., 2014. GIS-Based Landslide Susceptibility Mapping on the Peloponnese Peninsula, Greece, Geosciences, 4, 176-190.

Grinias, E., Atzemoglou, A. and Kotzinos, D., 2015. Design and Development of an OGC Web Processing Service as a Framework for Applying Ordinary Kriging in Groundwater Management. Chorografies, Biannual electronic magazine, Technical Educational Institute of Central Macedonia, Greece, (http://geo.teicm.gr/ojs/index.php/Chorografies/index),4(1), 1-8, ISSN:1792-3913.

IGME, Geological map of Greece, Sheets: Karpenissi, Agrafa, Thermo, Klepa, Fourna, Fragkista, Scale: 1:50000.

Keefer, D., 1984. Landslides caused by earthquakes, Geological Society of America, Bulletin, 95, 406-421.

Locat, J. and Leroueil, S., 1997. Landslide stages and risk assessment issues in sensitive clays and other soft sediments, Landslide Risk Assessment, Cruden and Fell, eds, Rotterdam, ISBN 9054109149.

Mountrakis, D., 1987. Geology of Greece, Thessaloniki, University Publications, 257 pp.

Neuhauser, B. and Terhorst, B., 2007. Landslide susceptibility assessment using "weights-of evidence" applied to a study area at the Jurassic escarpment (SW-Germany), Geomorphology, 86, 12-24. 
Papadopoulos, G. and Plessa, A., 2000. Magnitude-distance relations for earthquake-induced landslides in Greece, Engineering Geology, 58, 377-386.

Petley, D.N., Crick, W.D.O. and Hart, A.B., 2002. The Use of Satellite Imagery in Landslide Studies in High Mountain Areas, 23rd Asian Conference on Remote Sensing (ACRS), 25-29.

Vasileiadis, E., 2000. Landslides' hazard zonation of the Greek area, $\mathrm{PhD}$ (in Greek).

Thiery, Y., Malet, J.P., Sterlacchini, S., Puissant, A. and Maquaire, O., 2007. Landslide susceptibility assessment by bivariate methods at large scales: application to a complex mountainous environment, Geomorphology, 92, 38-59.

[1] INSPIRE: Directive 2007/2/EC of the European Parliament and of the Council of 14 March 2007 establishing an Infrastructure for Spatial Information in the European Community, http://inspire.ec.europa.eu.

[2] JRC, Joint Research Centre, https://ec.europa.eu/jrc/.

[3] Corine Land Cover 2000 (www.eea.europa.eu).

[4] www.w3c.org - World Wide Web (W3C) Consortium: The W3C is a global organization responsible for establishing standards, produce initiatives and manage the evolution of the web. W3C is responsible for standards like HTML, RDF, etc.

[5] Linked Open Data. http://linkeddata.org/ "The Semantic Web is a Web of Data - of dates and titles and part numbers and chemical properties and any other data one might conceive of. The collection of Semantic Web technologies (RDF, OWL, SKOS, SPARQL, etc.) provides an environment where application can query that data, draw inferences using vocabularies, etc.”. Copied from http://www.w3.org/standards/semanticweb/data - entry web site for all Linked Data related activities at W3C.

[6] RDF: Resource Description Framework, http://www.w3.org/RDF/

[7] SPARQL Protocol and RDF Query Language, http://www.w3.org/TR/sparq111-overview/

[8] The CIDOC CRM is ontology - a form of knowledge representation. An ontology represents the categorical knowledge within a domain. The function of domain ontology is to mediate the variability within a domain and provide a framework under which we can collaborate, http://www.ics.forth.gr/index_main.php?l=e\&searchtype=st_p\&c=229\&i=.

[9] GML: Geography Markup Language, http://www.opengeospatial.org/standards/gml.

[10] OWL: Web Ontology Language, http://www.w3.org/TR/owl2-overview/.

[11] URI: In computing, a Uniform Resource Identifier (URI) is a string of characters used to identify the name of a resource.

[12]OGC: The Open Geospatial Consortium, an international voluntary organization collaborate in a consensus process encouraging development and implementation of open standards for geospatial content and services, GIS data processing and data sharing.

[13] ISO: http://www.iso.org/iso/home/store/catalogue_tc/catalogue_detail.htm?csnumber=53798

[14] XML: Extensible Markup Language (XML) is a markup language that defines a set of rules for encoding documents in a format which is both human and machine-readable.

[15] INGEOCLOUDS was a 30-month project co-funded by EU. One of its main aims is to provide tools, methodologies and proof-of-concept implementations for storing, managing and retrieving geospatial data in a cloud based data infrastructure. More can be found at http://www.ingeoclouds.eu/.

[16] WxS services: A Web Map Service (WMS) provides an interface for requesting geo-registered map images from one or more distributed geospatial databases. A Web Feature Service (WFS) provides an interface allowing requests for geographical features across the web using platform-independent calls. A Web Processing Service (WPS) allows the publication of geospatial algorithms as web services giving the ability to the users to use this type of services without requiring any prior knowledge on how the specific algorithm can be implemented. More at http://www.opengeospatial.org/standards. 